ORIGINAL ARTICLE

\title{
Management of Post Tracheotomy Hemorrhage and Evaluation of Causing Factors
}

BAKHT ZADA ${ }^{1}$ ZAFAR IQBAL 2 , TAHIR MUHAMMAD ${ }^{3}$, REHAN SALEEM ${ }^{4}$, MUHAMMAD MUHAMMAD HABIB ${ }^{6}$

${ }^{1}$ ENT Head \&Neck Surgery, Lady Reading Hospital MTI, Peshawar

${ }^{2}$ Associate Professor ENT, Azra Nahid Medical College, Lahore

${ }^{3}$ Assistant Professor Department of ENT, Lady Reading Hospital, Peshawar

${ }^{4}$ Senior Registrar ENT department, Azra Nahid Medical College, Lahore

${ }^{5}$ Assistant Professor ENT Aziz Bhatti Shaheed Teaching Hospital/ Nawaz Sharif Medical College, Gujrat

${ }^{6}$ Associate Professor ENT Peshawar Medical College, Peshawar

Corresponding author: Dr. Tahir Muhammad, Email: drtahirent@gmail.com, Cell No: +923149768440

\begin{abstract}
Objective: To understand the frequency, causes, and treatment of post-tracheostomy hemorrhage.

Study Design: A prospective study of tracheostomy cases.

Place and duration: ENT, Head \& Neck Surgery department of Lady Reading Hospital MTI, Peshawar and Azra Nahid Medical College, Lahore for duration of one year from July 2019 to June 2020.

Methodology: All hospitalized patients who underwent tracheostomy and had bleeding during this period were included. The parameters specified were demographics, time since surgery, degree of bleeding, causes of bleeding, and treatment. A total of 208 patients who have done with tracheostomy were selected.

Results: Tracheostomy was performed in a total of 208 patients, 142 men and 66 women. Their ages ranged from 20 to 70 years old. 22 patients $(10.6 \%$ ) had postoperative bleeding, most of them have oozingfrom or around the stoma, but 5 patients were taken to the operating room for hemostasis. Three of them had Tracheoinnominate artery fistula and two died before undergoing surgery. One of the three trachea-innominatefistulae were successfully treated by a cardiac surgeon. The remaining cases required diathermy, transfixing thyroid isthmus or vein descent or relegation of veins.

Conclusions: Hemorrhage after tracheostomy is not uncommon in intensive practice, bleeding occurred in $10.5 \%$ of our cases. Hemorrhage occurs because of inadequate hemostasis, aspiration trauma, infection, coagulopathy and granulation. Rarely, there may be massive and life-threatening bleeding from tracheo-innominate fistula that requires aggressive and urgent exploration. In such a situation, an experienced cardiac surgeon and anesthesiologist is very important and can lead to a better result.
\end{abstract}

Key words: Tracheostomy, post-tracheostomy hemorrhage, Tracheo-innominate artery fistula (TIF)

\section{INTRODUCTION}

One of the oldest surgical procedures described, the tracheostomy, was first described in the 1st century BC and is still a common procedure in busy ENT practice ${ }^{1-2}$. This life-saving procedure is best performed in the operating room using the standard technique described by Jackson in $1909^{3-4}$. It is now also performed at the patient's bedside, known as percutaneous dilatation tracheostomy. Some of the common complications include airway obstruction, aspiration, bleeding, infection, and damage to the laryngeal nerve; Of course, these complications are exacerbated with emergency tracheostomy ${ }^{5-6}$. Hemorrhagemay occur during surgery / immediately within 24 hours of the postoperative period, or within a week of the early postoperative period, emphasizing the importance of postoperative care, with late bleeding occurring one week after surgery ${ }^{7-8}$. Insufficient hemostasis, coagulopathies, ligation slippage and thyroid bleeding are some of the causes of early postoperative bleeding, while late causes include granulation, infection, tracheo innominate fistula (TIF) and suction trauma ${ }^{9-10}$. The aim of this prospective study is to highlight the causes of post-tracheostomy hemorrhage and appropriate TIF management in our hospital.

\section{METHODOLOGY}

This is a prospective study of all hospitalized patients requiring tracheostomy at the ENT, Head \& Neck Surgery department of Lady Reading Hospital MTI, Peshawar and Azra Nahid Medical College, Lahore for duration of one year from July 2019 to June 2020.A total of 208 patients were selected, 142 men and 66 women who required Tracheostomy. Children under the age of 15 were excluded from the study because they were led by pediatric surgeons at our hospitals. Data were analyzed for the following demographic parameters, time since tracheostomy, degree of bleeding, cause (s) of bleeding, and treatment applied.

\section{RESULTS}

Tracheostomy was performed in a total of 208 patients, 142 men and 66 women with a male to female ratio of 1.2: 1 . Their ages ranged from 20 to 70 years old with a median of 42 and mean age of 45-years (Table-1).

The demographic features of patients are given in Table 1

\begin{tabular}{|l|l|l|}
\hline Male $(\mathrm{n})$ & 142 & $68.3 \%$ \\
\hline Female $(\mathrm{n})$ & 66 & $31.7 \%$ \\
\hline Age Range (years) & $20-70$ & \\
\hline Mean Age (years) & 45 & \\
\hline Median Age (years) & 42 & \\
\hline Age Group & \multicolumn{2}{|l|}{} \\
\hline $20-40$ & 98 & $47.1 \%$ \\
\hline $40-60$ & 74 & $35.6 \%$ \\
\hline $60-70$ & 36 & $17.3 \%$ \\
\hline
\end{tabular}


Most of the cases came from the surgical, medical, thoracic, and stroke intensive care units. The most common indication for tracheostomy was chronic obstructive airway disease (51.9\%), followed by trauma and vascular stroke (Table 2).

Various indications of Tracheostomy are given in Table-2
\begin{tabular}{|l|l|l|}
\hline Indications & Frequency (n) & Percentage (\%) \\
\hline COPD & 108 & $51.9 \%$ \\
\hline Trauma & 64 & $30.8 \%$ \\
\hline $\begin{array}{l}\text { Cerebrovascular } \\
\text { accidents }\end{array}$ & 17 & $8.2 \%$ \\
\hline $\begin{array}{l}\text { Head and Neck } \\
\text { tumors }\end{array}$ & 8 & $3.8 \%$ \\
\hline Meningitis & 6 & $2.9 \%$ \\
\hline Tetanus & 5 & $2.4 \%$ \\
\hline Total & 208 & 100 \\
\hline
\end{tabular}

22 patients (10.6\%) had some type of hemorrhage after tracheostomy. There was no intraoperative bleeding. The causes of post-tracheostomy bleeding included suppuration / infection of the wound, coagulopathy, suction trauma, severe ligation bleeding, granulation tissue, thyroid bleeding, and TIF (Table 3).

Table-3

\begin{tabular}{|l|l|l|}
\hline Cause & Frequency $(\mathrm{n})$ & Percentage $(\%)$ \\
\hline $\begin{array}{l}\text { Wound } \\
\text { infection/oozing }\end{array}$ & 6 & $27.3 \%$ \\
\hline Suction trauma & 3 & $13.6 \%$ \\
\hline Ligature slippage & 2 & $9.1 \%$ \\
\hline TIF & 3 & $13.6 \%$ \\
\hline Coagulopathy & 2 & $9.1 \%$ \\
\hline Granulations & 3 & $13.6 \%$ \\
\hline Thyroid bleed & 3 & $13.6 \%$ \\
\hline Total & 22 & 100 \\
\hline
\end{tabular}

5 patients were taken to the operating room for hemostasis. Three of them had Tracheo- innominate artery fistula and two died before undergoing surgery. One of the three trachea-innominate fistulae were successfully treated by a cardiac surgeon. The remaining cases required diathermy, transfixing thyroid isthmus or vein descent or relegation of veins.

\section{DISCUSSION}

A tracheostomy is a simple yet life-saving surgical procedure with few complications if performed correctly ${ }^{11-12}$. As with Amus et al., More men underwent tracheostomy in this study. This was probably because men smoke more and suffer injuries more, as the two most common indications for a tracheostomy were chronic obstructive airway disease and trauma ${ }^{13-14}$. Bleeding after tracheostomy is a very critical problem and is estimated to be around 3\%. Of the 208patients in our study, 22 had some type of bleeding after tracheostomy. Most cases bleed immediately after surgery, but in some cases, bleeding is delayed. This result is in agreement with Allan et al. Initial hemorrhages were mainly due to wound discharge, infection, aspiration trauma, ligament sliding, and bleeding / coagulation abnormalities ${ }^{15-16}$. While most of these patients were treated with simple measures such as proper wound care, compression with antiseptic gauze and absorbable gauze, patients with coagulopathy also required a fresh frozen plasma transfusion ${ }^{17}$. The causes of the late bleeding were likely due to wound infection, granulation and TIF. Before all these life-threatening events, 2-3 days ago, there were small spots of blood known as "paroxysmal bleeding". The incidence of TIF is reported as $0.3-0.7 \%$. The incidence rate in this study was $1.4 \%(3 / 208)$, which is slightly higher than reported in the literature ${ }^{18-19}$. Mortality from TIF is $50-70 \%$. Some ITFs have also been reported after percutaneous dilating tracheostomy, but none have been reported in our previous series. One of the three TIF cases in this study died before adequate surgical assistance could be arranged to reduce the severity of the condition $^{20-21}$. Two other TIF patients had successful outcomes with prompt and effective first aid until an anesthetist and cardiac surgeon specialist arrived in the operating room ${ }^{22}$. First aid measures included over-inflation of the tracheostomy cuff (Fig. 1), digitally pressing the nameless vessels against the handpiece (Fig. 2), while ensuring that the tracheostomy tube was not removed until the cardiac surgeon was in the operating room.

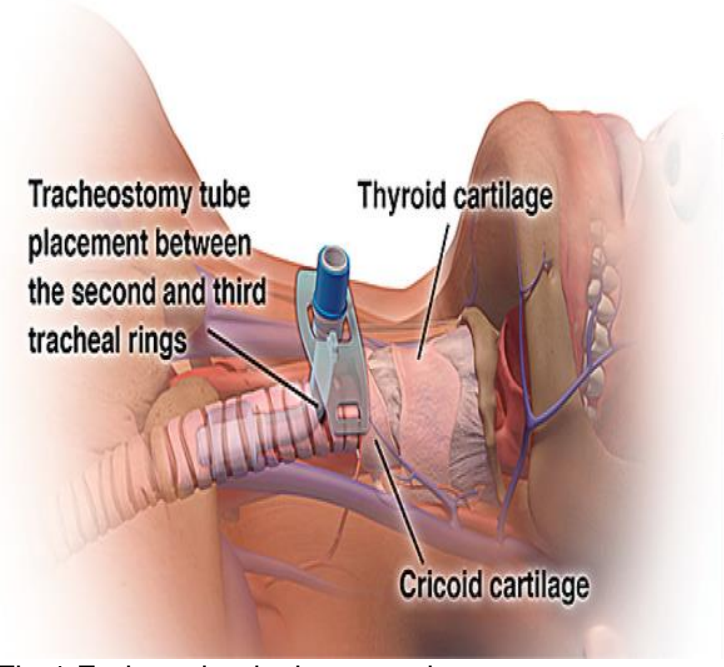

Fig-1 Endotracheal tube procedure

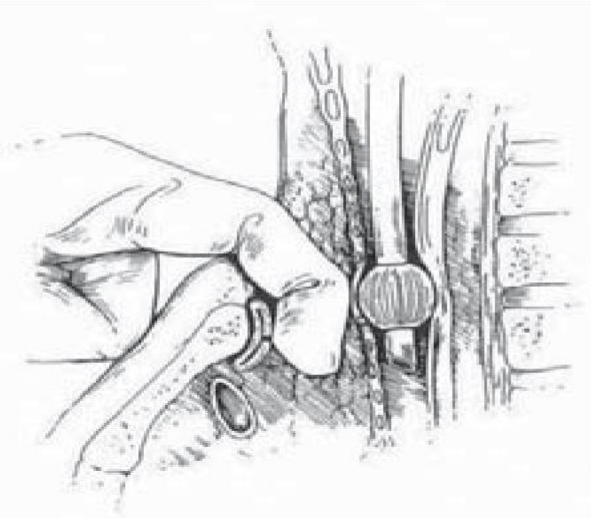

Fig-2 shows Innominate vessel pressed against sternum 
An endoscopy was also performed to view the fistula, followed by a sternotomy, and then the fistula was repaired with a pericardial graft. Singh et al. Also recommend this when treating an 80-year-old patient with uncomplicated TIF bleeding $23-24$.

\section{CONCLUSION}

Post-tracheostomy bleeding is not an uncommon problem; some bleeding occurred in about $10.5 \%$ of our cases. Most of the early bleeding events are mild and can be managed with medical care. Late bleeding can be caused by TIF, about $50-70 \%$ of which may be fatal. Prompt and effective TIF first aid is important for better outcomes and should be continued until a trained team of experienced cardiac surgeons and anesthetists arrives. Over inflation of the tracheostomy cuff, pressing innominate vessels against the manubrium, not to remove the tracheostomy tube, and proper blood replacement are the keys to successful initial TIF treatment. Tracheostomy should be removed only after all specimens have been prepared for examination, therefore flexible / rigid bronchoscopy should be attempted to determine the cause and location of the bleeding.

\section{REFERENCES}

1. Goetz C, Burian NM, Weitz J, Wolff KD, Bissinger $\mathrm{O}$. Temporary tracheotomy in microvascular reconstruction in maxillofacial surgery: Benefit or threat?. Journal of CranioMaxillofacial Surgery. 2019 Apr 1;47(4):642-6.

2. Abe $A$, Ito $\mathrm{Y}$, Hayashi $\mathrm{H}$, Furuta $\mathrm{H}$, Ishihama $\mathrm{T}$, Adachi $\mathrm{M}$. The degree of agreement between score-based decision and clinician's discretion regarding the need for tracheotomy in oral cancer surgery: A retrospective analysis. Medicine. $2021 \mathrm{Jul}$ 30;100(30).

3. Moussa MK, Moussa A, Nasr F, Khalaf Z, Sarout S, Moukarzel N, Dib A. Comparison of the Outcomes of Early Versus Late Tracheostomy in the Treatment of Critically III Patients: A Retrospective Multicenter Measurement Study Done in Two Hospital Centers in Lebanon. Cureus. 2020 Nov;12(11).

4. Boran Ö, Bilal B, Bilal N, Öksüz H, Boran M, Yazar FM. Comparison of the efficacy of surgical tracheostomy and percutaneous dilatational tracheostomy with flexible lightwand and ultrasonography in geriatric intensive care patients. Geriatrics \& gerontology international. 2020 Mar;20(3):201-5

5. Koizumi M, Ishimaru M, Matsui $H$, Fushimi $K$, Yamasoba $T$, Yasunaga $\mathrm{H}$. Factors associated with the occurrence of stomal stenosis after tracheostomy in adults. AurisNasus Larynx. 2021 Apr 26.

6. O'Malley TJ, Jordan AM, Prochno KW, Saxena A, Maynes EJ, Ferrell B, Guy TS, Entwistle JW, Massey HT, Morris RJ, Abai B. Evaluation of Endovascular Intervention for TracheoInnominate Artery Fistula: A Systematic Review. Vascular and endovascular surgery. 2021 May;55(4):317-24.

7. Mehel DM, Özdemir D, Celebi M, Aydemir S, Akgül G, Özgür A. Classification of laryngeal injury in patients with prolonged intubation and to determine the factors that cause the injury. American journal of otolaryngology. 2020 May 1;41(3):102432.

8. Panuganti BA, Weissbrod PA, Somal J. Critical Care and Postoperative Management of the Head and Neck Patient. Otolaryngologic Clinics of North America. 2019 Dec $1 ; 52(6): 1141-56$
9. Abhiram K, Agnieszka D, Allemang M, Santoscoy $T$. Emergent Management of a Tracheoinnominate Fistula in the Community Hospital Setting. Cureus. 2020;12(6).

10. Fuller C, Andre'M W, Richter GT. Update on Pediatric Tracheostomy: Indications, Technique, Education, and Decannulation. Current Otorhinolaryngology Reports. 2021 Apr 15:1-2.

11. Botti C, Lusetti F, Neri T, Peroni S, Castellucci A, Salsi P Ghidini A. Comparison of percutaneous dilatational tracheotomy versus open surgical technique in severe COVID-19: Complication rates, relative risks and benefits. AurisNasus Larynx. 2021 Jun 1;48(3):511-7.

12. Dahill KE, Dempsey G. Tracheocarotid artery fistula in a patient who had tracheostomy successfully treated with a saphenous vein graft. BMJ Case Reports CP. 2021 Mar 1;14(3):e237854.

13. Barash M, Kurman JS. Patient selection and preoperative evaluation of percutaneous dilation tracheostomy in the intensive care unit.

14. Lüsebrink E, Krogmann A, Tietz $F$, Riebisch M, Okrojek R, Peltz F, Skurk C, Hullermann C, Sackarnd J, Wassilowsky D, Toischer K. Percutaneous dilatational tracheotomy in high-risk ICU patients. Annals of Intensive Care. 2021 Dec;11(1):1-0.

15. Bontempo LJ, Manning SL. Tracheostomy emergencies. Emergency Medicine Clinics. 2019 Feb 1;37(1):109-19.

16. Abe A, Kurita K, Ito $\mathrm{Y}$, Hayashi H, Umemura $\mathrm{E}$, Adachi M. Assessment of the degree of agreement between the judgment of tracheotomy score and the clinician: a retrospective analysis.

17. Kondajji A, Dombrowska A, Allemang M, Santoscoy $T$. Emergent Management of a Tracheoinnominate Fistula in the Community Hospital Setting. Cureus. 2020 Jun;12(6).

18. Huston MN, Naunheim KS, Naunheim MR. Managing Otolaryngologic Complications in Cardiothoracic Surgery. The Annals of thoracic surgery. 2020 Aug 1;110(2):676-83.

19. Kristensen MS, McGuire B. Managing and securing the bleeding upper airway: a narrative review. Canadian Journal of Anesthesia/Journal canadiend'anesthésie. 2020 Jan;67(1):128-40.

20. Cai TY, Zhang WB, Yu Y, Wang Y, Mao C, Guo CB, Yu GY, Peng $X$. Scoring system for selective tracheostomy in head and neck surgery with free flap reconstruction. Head \& neck. 2020 Mar;42(3):476-84.

21. Hu H, Wu F, Zhang J, Chen E. Treatment of secondary benign airway stenosis after tracheotomy with Montgomery T-tube. Mathematical Biosciences and Engineering. 2019 Aug 27;16(6):7839-49.

22. Tornari C, Surda P, Takhar A, Amin N, Dinham A, Harding R, Ranford DA, Archer SK, Wyncoll D, Tricklebank S, Ahmad I. Tracheostomy, ventilatory wean, and decannulation in COVID-19 patients. European Archives of Oto-Rhino-Laryngology. 2021 May;278(5):1595-604.

23. Yoshimatsu $\mathrm{Y}$, Tobino $\mathrm{K}$, Maeda K, Kubota K, Haruta $\mathrm{Y}$, Adachi $\mathrm{H}$, Abe $\mathrm{T}$, Masunaga $\mathrm{T}$, Sueyasu T, Osaki T. Management of airway obstruction due to diffuse idiopathic skeletal hyperostosis in the cervical spine: a case report and literature review. Internal Medicine. 2019:1071-8.

24. Schmidt M, Fisser C, Martucci G, Abrams D, Frapard T, Popugaev K, Arcadipane A, Bromberger B, Lino G, Serra A, Rozencwajg $S$. Tracheostomy management in patients with severe acute respiratory distress syndrome receiving extracorporeal membrane oxygenation: an International Multicenter Retrospective Study. Critical Care. 2021 Dec;25(1):1-1. 